British Journal of Nutrition (2021), 126, 1564-1570

doi: $10.1017 /$ S000711452000361X

(C) The Author(s), 2020. Published by Cambridge University Press on behalf of The Nutrition Society. This is an Open Access article, distributed under the terms of the Creative Commons Attribution licence (http://creativecommons.org/licenses/by/4.0/), which permits unrestricted re-use, distribution, and reproduction in any medium, provided the original work is properly cited.

\title{
Probiotics and Coronavirus disease 2019: think about the link
}

\author{
Suresh Kumar Angurana and Arun Bansal* \\ Division of Pediatric Critical Care, Department of Pediatrics, Advanced Pediatrics Centre, Postgraduate Institute of Medical \\ Education and Research (PGIMER), Chandigarh 160012, India
}

(Submitted 27 June 2020 - Final revision received 1 September 2020 - Accepted 2 September 2020 - First published online 14 September 2020)

Abstract

The pandemic of Coronavirus disease 2019 (COVID-19) is rapidly progressing, causing significant morbidity and mortality. Various antiviral drugs, anti-inflammatory drugs and immunomodulators have been tried without substantial clinical benefits. The severe and critical cases of COVID-19 disease are characterised by gut microbiome dysbiosis, immune dysregulation, hyper-inflammation and hypercytokinaemia (cytokine storm). Therefore, the strategies which target these pathophysiological processes may be beneficial. Probiotics are one such strategy that exerts beneficial effects by manipulation of the gut microbiota, suppression of opportunistic pathogens in the gut, decreasing translocation of opportunistic organisms, activation of mucosal immunity and modulation of the innate and adaptive immune response. Probiotics are the potential candidates to be tested in moderate and severe cases of COVID-19 due to several beneficial effects, including easy availability, easy to administer, safe and economical to use.

Key words: Coronavirus disease 2019: Probiotics: Gut microbiome: Dysbiosis: Cytokine storm

The pandemic of severe acute respiratory syndrome Coronavirus-2, causing Coronavirus disease 2019 (COVID-19), is rapidly progressing with 25118689 cases and 844312 deaths all over the world with a mortality rate of $3.4 \%$ (the WHO dashboard as on 31 August 2020). The main reasons for the massive impact of COVID-19 are lack of preparedness for unprecedented and unexpected spread, intrinsic virulence of the pathogen and its contagiousness, asymptomatic spreaders, lack of effective vaccine, and lack of proven and effective antiviral drugs ${ }^{(1)}$.

\section{Hyper-inflammation in Coronavirus disease 2019}

The COVID-19 has a heterogeneous presentation and clinical course. The majority of cases are either asymptomatic or have mild symptoms ${ }^{(2-5)}$. The severe or critical diseases have been documented in $2-5 \%$ of cases. The mortality among patients admitted to intensive care units ranges from $30 \%$ to more than $60 \%{ }^{(6-9)}$. The severe COVID-19 is characterised by immune dysregulation, hyper-inflammation and hypercytokinaemia (cytokine storm or cytokine release syndrome). The level of cytokines (IL-1 $\beta$, IL-1ra, IL-2, IL-6, IL-10, IL-17, TNF, interferon- $\gamma$, granulocyte monocyte-colony stimulating factor, interferoninduced protein-10 and monocyte chemotactic protein-3) is higher in non-survivors or severe COVID-19 $9^{(10-16)}$. Therefore, with the onset of a cytokine storm, the antiviral drugs alone may not be sufficient and it is suggested to add anti-inflammatory treatment ${ }^{(1,16,17)}$.
In late April 2020, clinicians from the United Kingdom (UK) reported eight previously healthy children who presented with cardiovascular shock, fever and hyper-inflammation ${ }^{(18)}$. Subsequently, Pediatric inflammatory multisystem syndrome temporally associated with SARS-CoV-2 (PIMS-TS), multisystem inflammatory syndrome in children (MIS-C), Kawasaki disease and Kawasaki-like syndrome have been reported from the countries with high load of COVID-19 like UK, France, Italy and the $\mathrm{USA}^{(14,15,18-25)}$. Most of these children were treated with intravenous immunoglobulin (IVIG) and/or steroids.

\section{Gut-lung axis and gut microbiome in Coronavirus disease 2019}

In addition to alveolar epithelial cells, enterocytes also express angiotensin-converting enzyme 2 receptors and SARS-CoV-2 RNA has been demonstrated in the faeces of infected patients ${ }^{(16,26-28)}$. Also, SARS-CoV-2 can invade enterocytes, and therefore, the gut may act as a reservoir for the virus ${ }^{(29,30)}$. The interaction of SARS$\mathrm{CoV}-2$ with angiotensin-converting enzyme 2 receptors in the gut may be responsible for the gastrointestinal symptoms, which are noted in 12-60\% cases of COVID-19, and is associated with increased disease severity ${ }^{(31)}$.

There is evidence available to indicate the crosstalk between gut microbiota and lung (gut-lung axis). This axis maintains the host homoeostasis and may be altered in diseased states. The

Abbreviation: COVID-19, Coronavirus disease 2019.

* Corresponding author: Professor Arun Bansal, email drarunbansal@gmail.com 
gut-lung interaction is bidirectional, and the gut plays a vital role in influencing lung disease. In diseased states, the gut microbiome is disturbed (dysbiosis), leading to translocation of endotoxins and microbial metabolites from the gut, which can then impact the lung through the bloodstream. Similarly, when inflammation occurs in the lungs (e.g. respiratory viral infections), it causes perturbations in the gut microbiome (gut-lung axis) $)^{(16,32,33)}$

This bidirectional gut-lung interaction may be playing an important role in COVID-19, leading to increased disease severity. In extreme of ages and among those with underlying co-morbid conditions, the gut microbiota is less in diversity leading to gut dysbiosis ${ }^{(34-37)}$. This could be one of the reasons for the increased disease severity of COVID-19 among cases with the extreme of ages and in those with underlying co-morbid medical conditions ${ }^{(38,39)}$. It has been demonstrated that the gut microbiome is altered in cases with COVID-19 in terms of a significant reduction in diversity and number of beneficial gut microbiota and an increase in the number of opportunistic pathogens ${ }^{(16,40,41)}$. This can ultimately lead to gut dysbiosis, translocation of pathogenic organisms across the gut mucosa, secondary bacterial infections, enhanced inflammatory response, multiple organ dysfunction and poor clinical outcome. Zuo et $a l .{ }^{(41)}$ performed metagenomic sequencing analyses on the faecal samples of COVID-19 patients ( $n$ 15) from the time of admission until discharge and compared them with fifteen healthy controls. The authors demonstrated that these patients had significant depletion of beneficial commensals and enrichment of opportunistic pathogens at the time of admission as well as at all time points during the hospital stay when compared with controls. Similarly, Gu et al. ${ }^{(40)}$, in a cross-sectional study involving COVID-19 patients ( $n$ 30), demonstrated that the gut microbiome (faecal sample collected at admission) of COVID-19 cases had significantly reduced bacterial diversity, a lower count of beneficial symbionts and a higher number of opportunistic pathogens (Streptococcus, Rothia, Veillonella and Actinomyces).

Therefore, the heightened or dysregulated inflammation and gut dysbiosis may be the major pathophysiological processes in cases with COVID-19 leading to increased severity of illness and poor clinical outcomes.

\section{Current treatment strategies for Coronavirus disease 2019}

The therapies such as antiviral drugs that inhibit the viral entry and/or replication (remdesivir, favipiravir and lopinavirritonavir) and drugs/strategies that modulate the cytokine storm (hydroxychloroquine, chloroquine, azithromycin, JAK inhibitors, IL- 6 inhibitors, IL- 1 inhibitors, anti-TNF- $\alpha$ agents, corticosteroids, IVIG, tocilizumab, colchicine and plasma therapy) have been the focus of research in COVID-19 but without much clinical success ${ }^{(42-51)}$ (Fig. 1).

\section{Probiotics in Coronavirus disease 2019}

In the absence of proven effective therapy for COVID-19, the treatment is mainly supportive. Therefore, the alternative strategies that target pathophysiological pathways in patients with
COVID-19 need to be tested. One such approach is probiotics. The WHO and FAO defined probiotics as live microorganisms which, when administered in adequate amounts, confer a health benefit on the host.' Many different micro-organisms have been considered as probiotics, including Lactobacillus species (L. acidophilus, L. casei and L. rhamnosus); Bifidobacterium species (B. bifidum, B. longum and B. lactis); Enterococcus species (E. faecalis and E. faecium) and Saccharomyces (S. boulardii and $S$. cerevisiae). The most commonly used strains are Lactobacillus and Bifidobacterium ${ }^{(52)}$.

\section{Restoration of the gut microbiome by probiotics}

Probiotics exert their beneficial effects through various mechanisms including manipulation and restoration of gut microbiota, enhancement of intestinal barrier function, competition with pathogens for adhesion to gut epithelium and nutrition, suppression of opportunistic pathogens, production of antimicrobial substances, decrease in translocation of opportunistic organisms, activation of mucosal immunity and modulation of the innate and adaptive immune response ${ }^{(29,52-57)}$. These actions of probiotics have been proven in various experimental ${ }^{(58-60)}$ and clinical studies ${ }^{(55,61-66)}$.

It is important to note that not all probiotic strains exert the same actions ${ }^{(29)}$. The combination of multiple strains may exert one or a few of these actions and thus act synergistically. Therefore, multistrain probiotics could be more effective than mono-strain probiotics ${ }^{(67)}$. A review comparing single strain and multistrain probiotics demonstrated that the multistrain probiotics had greater efficacy than individual strains, including single strains that were components of the mixtures themselves ${ }^{(68)}$.

Due to the beneficial effects of probiotics on gut microbiota, they have been tested to prevent various infective complications among hospitalised patients. Many strain of probiotics has been demonstrated to be safe and effective in the prevention of Clostridium difficile-associated diarrhoea among hospitalised children and adults ${ }^{(69,70)}$ and secondary bacterial infections including ventilator-associated pneumonia in critically ill patients ${ }^{(71-74)}$, postoperative infections (respiratory, urinary tract and wound infections) in patients undergoing gastrointestinal surgery ${ }^{(75)}$ and candida colonisation in the gastrointestinal tract and invasive candidiasis in critically ill children ${ }^{(52-54)}$. Systematic reviews and meta-analysis involving critically ill adults demonstrated that probiotic supplementation has been associated with decreased risk of nosocomial infections, lesser gastrointestinal complications, lower mortality and shortened ICU stays ${ }^{(76-78)}$. Among preterm neonates, a meta-analysis ( $n$ 8000) demonstrated that supplementation with certain probiotics resulted in a reduction in necrotising enterocolitis, nosocomial sepsis and all-cause mortality ${ }^{(79)}$.

Since the gut microbiome is altered in cases with COVID$19^{(16,40,41)}$, some strain of probiotics may help in restoring the gut microbiota, maintain a healthy gut-lung axis, lesser translocation of pathogenic bacteria across gut mucosa and lesser chances of secondary bacterial infections. Similar actions have been demonstrated in several experimental and clinical studies ${ }^{(55,58-66,80,81)}$. The findings of these studies can be extrapolated and need to be tested in cases with COVID-19. 


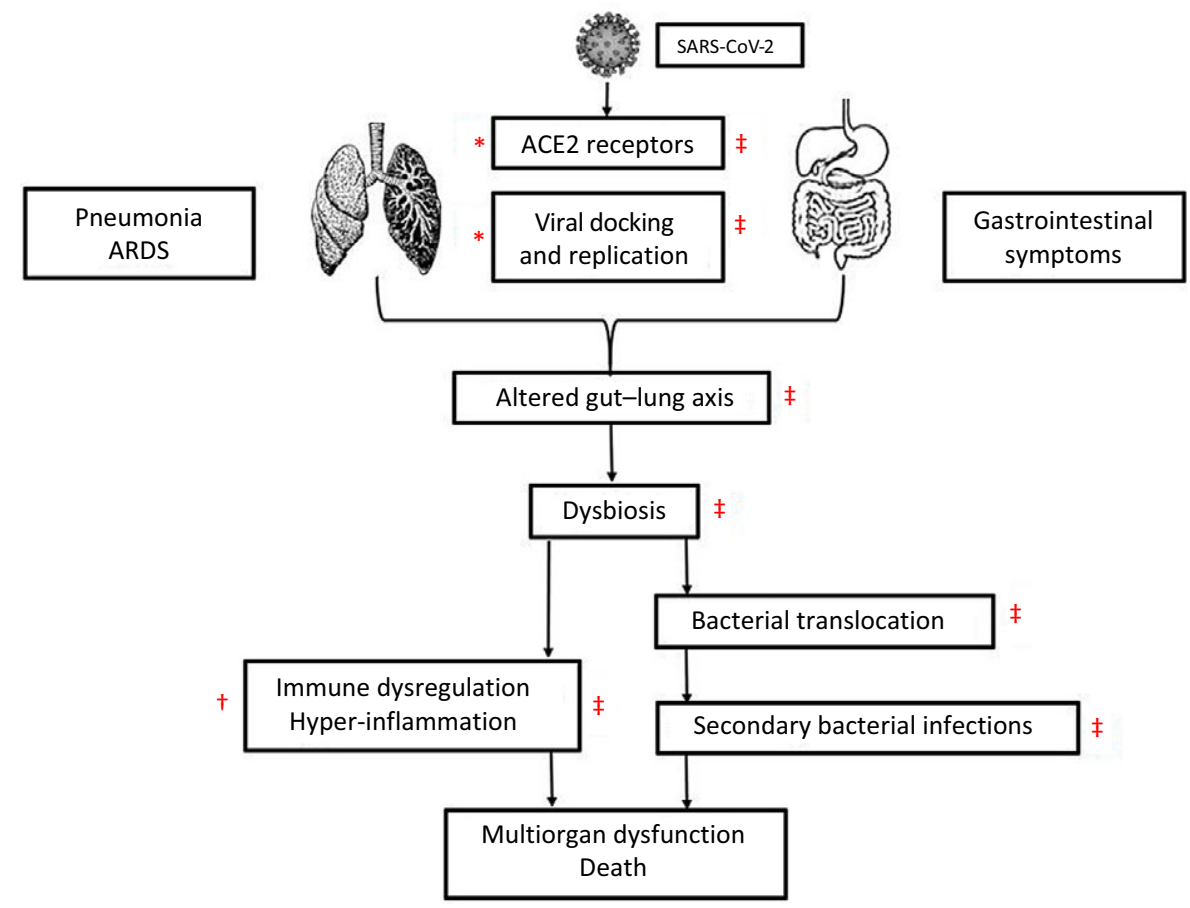

Fig. 1. The figure shows a cascade of the pathogenesis of COVID-19 and site of action of antiviral, anti-inflammatory drugs and probiotics. The antiviral drugs act at viral docking, entry and viral replication stage $\left({ }^{*}\right)$. Anti-inflammatory drugs act at the stage of hyper-inflammation (†). Probiotics may act at multiple stages as viral docking, entry and replication, restoration of gut microbiota and gut-lung axis, reduction in bacterial translocation and secondary bacterial infection, and modulation of hyperinflammation (cytokine storm) (ł).SARS nCoV-2, severe acute respiratory syndrome Coronavirus-2; ACE2, angiotensin-converting enzyme 2;

\section{Modulation of inflammation by probiotics}

The role of probiotics in the modulation of inflammation has been demonstrated in clinical studies involving children and adults in health and several diseased states ${ }^{(55,62,63,65,66,82-85)}$. Kazemi et al. ${ }^{(82)}$, in a recent systematic review and meta-analysis, analysed 167 clinical trials that investigated the effect of oral probiotics or synbiotic (for $>1$ week) on inflammatory markers (C-reactive protein, IL-1 $\beta$, IL-4, IL-6, IL-8, IL-10, IL-12, TNF- $\alpha$, interferon $\gamma$ and transforming growth factor- $\beta$ ) among healthy individuals and in various disease conditions. Authors noted that some probiotics lead to decrease in C-reactive protein levels in healthy individuals, metabolic disorders, inflammatory bowel disease, arthritis and critically ill condition; decrease in TNF- $\alpha$ levels in healthy individuals, fatty liver, inflammatory bowel disease and hepatic cirrhosis; increase in IL-6 in cirrhosis and renal failure; and increase in IL-10 in arthritis. In another meta-analysis (eight clinical trials, 1337 patients with diabetes), it has been demonstrated that probiotics and synbiotic supplementation significantly decreased C-reactive protein and TNF- $\alpha$ levels but did not affect IL-6 levels ${ }^{(83)}$. These meta-analyses suggest that supplementation with probiotics leads to a decrease in proinflammatory markers (hs-C-reactive protein, TNF-a, IL-6, IL-12, IL- 4 and TNF- $\alpha$ ) and an increase in anti-inflammatory cytokines (IL-10) in healthy and several diseased states ${ }^{(82-84)}$.

In an RCT ( $n$ 100), Angurana et al. ${ }^{(55)}$ demonstrated that administration of a multistrain probiotic (Lactobacillus paracasei, L. plantarum, L. acidophilus, L. delbrueckii, Bifidobacterium longum, B. infantis, B. breve and Streptococcus salivarius) to critically ill children with severe sepsis for 7 days resulted in a significant decrease in levels of pro-inflammatory cytokines
(IL-6, IL-12p70, IL-17 and TNF- $\alpha$ ) and increase in antiinflammatory cytokines (IL-10 and transforming growth factor- $\beta 1$ ) as compared with placebo. Other studies also demonstrated that certain probiotics were useful in the modulation of inflammation in critically ill patients ${ }^{(66,85)}$.

As cytokine storm occurs in patients with severe COVID-19, the effect of probiotics on pro-inflammatory and immunoregulatory cytokines allows viral clearance and minimise immune response-mediated tissue damage in the lungs and other organs. So, these immune-modulatory effects of probiotics might be relevant to prevent lung injury, acute respiratory distress syndrome (ARDS) and multiple organ dysfunction syndrome which are significant complications of COVID-19(29).

\section{Antiviral effects of probiotics}

The antiviral effects of probiotics have been demonstrated in experimental and clinical studies. Few experimental studies showed that various strains of probiotics exert antiviral effect by impairing virus entry into human cells and preventing viral replication ${ }^{(86-89)}$. Ang et al. ${ }^{(86)}$, in an in vitro study involving human skeletal muscle and colon cell lines, demonstrated that Lactobacillus reuteri Protectis showed significant dosedependent antiviral activity against Coxsackievirus type A strains 6 and 16 and enterovirus 71. Lee et al. ${ }^{(87)}$ studied the in vitro (Vero cell) antiviral activity of probiotics against Rotavirus and demonstrated that B. longum and L. acidophilus have an inhibitory effect on the Rotavirus. Similarly, other studies also showed the antiviral and immunogenic action of probiotics (Lactobacillus and Bifidobacterium) against the Influenza virus, Respiratory syncytial virus and Rotavirus ${ }^{(90-94)}$. 
Viruses are the most frequent cause of upper respiratory tract infections. A Cochrane review (twelve RCT with 3720 participants, including children and adults) showed that probiotics were superior to placebo in decreasing the number of participants experiencing episodes of acute upper respiratory tract infections, mean duration of an episode of acute upper respiratory tract infections, antibiotic use and cold-related school absenteeism ${ }^{(95)}$. In influenza viral infection, probiotics have been shown to modulate respiratory immunity and had a beneficial impact on virus clearance and inflammatory-mediated lung injury ${ }^{(96)}$.

Recently, Anwar et al. ${ }^{(88)}$, in a computational docking study, demonstrated that three metabolites of Lactobacillus plantarum (Plantaricin W, Plantaricin JLA-9 and Plantaricin D) significantly blocked the binding of SARS-CoV-2 with angiotensin-converting enzyme 2 receptors (blocking the viral entry into the cells) and suggested antiviral property of Lactobacillus plantarum against SARS-COV-2.

Therefore, probiotics may act as antiviral agents by interfering with the viral entry into cells and/or inhibit virus replication. This may lead to a reduction in the dissemination of SARS-CoV-2 in the respiratory tract and gut. Also, with the restoration of the gut and respiratory microbiota, immune function and gut-lung axis, the course of COVID-19 may be altered ${ }^{(29)}$.

\section{Safety of probiotics}

Most of the probiotic strains are generally safe even in the vulnerable population and in an intensive care setting, including neonates, children and adults. Many probiotic strains have shown beneficial effects in these settings ${ }^{(52-55,61-66,69-79,82-85,97)}$. However, there are few case reports of probiotic-associated bacteraemia, infective endocarditis, liver abscesses and fungaemia. These are majorly reported in severely debilitated cases, premature babies and immunocompromised patients who were treated with preparations lacking adequate quality control ${ }^{(98-104)}$.

It has been suggested to exercise caution while using probiotics in the presence of a one major risk factor (immunocompromised state and premature infants) or more than one minor risk factor (central venous catheter, cardiac valvular disease, impaired intestinal epithelial barrier, administration of probiotics by jejunostomy and probiotics with properties of high mucosal adhesion or known pathogenicity) because of the risk of probiotics-sepsis $^{(80,105)}$.

Other safety concerns are the genetic transfer of antimicrobial resistance from probiotic strains to pathogenic organisms in the gut (particularly Staphylococcus aureus and Enterococcus) ${ }^{(106,107)}$, deleterious metabolic activities and excessive immune stimulation in susceptible individuals ${ }^{(52,80)}$. The use of probiotics may be limited in the presence of immunocompromised states or premature neonates because of safety concerns, as discussed above. The supplementation with probiotics may not be possible in whom enteral administration is contraindicated.

\section{The rationale for using probiotics in Coronavirus disease 2019}

Several clinical trials of antiviral and anti-inflammatory drugs are in progress to evaluate the therapeutic effects of these drugs in patients with COVID-19(108). The site of action of currently used antiviral and anti-inflammatory medications is at limited steps in the pathogenesis of COVID-19 (Fig. 1). The probiotics, such as Lactobacillus and Bifidobacterium, possibly act at multiple levels in this cascade of COVID-19. They act through antiviral actions ${ }^{(86-96)}$, restoration of the gut microbiome ${ }^{(55,58-66,80,81)}$, modulation of inflammation/cytokine storm (anti-inflammatory) $)^{(55,62,63,65,66,82-85)}$ and prevention of secondary bacterial and fungal infections ${ }^{(52-54,69-75)}$ (Fig. 1). Though the evidence for the rationale of using probiotics to treat COVID-19 comes from indirect evidence, these actions of probiotics may help in the prevention of and/or alleviation of COVID-19 related symptoms and complications. Moreover, probiotics are readily available, easy to administer (oral administration), relatively safe and economical compared with antiviral drugs, immunomodulators or other strategies tested in COVID-19(1).

Therefore, probiotics, due to their mechanisms of action, are a potential strategy that need to be tested in moderate to severe cases with COVID-19 by conducting well-designed clinical trials. Few registered trials are going on to evaluate the possible beneficial effects of probiotics supplementation in cases with COVID-19 (NCT04366180, NCT04368351 and NCT04366089).

A better understanding of the pathophysiology of COVID-19 and the results of the clinical trials will guide further on the efficacy, benefits and safety of probiotics in COVID-19. Despite these limitations, considering various mechanisms of actions of probiotics on the regulation of gut dysbiosis and anti-inflammatory activity, and clinical evidence about the beneficial effects of probiotics in critically ill adults and children, probiotics are a potential therapeutic strategy that need to be tested in moderate to severe cases with COVID-19.

\section{Conclusion}

Some probiotics may have a beneficial role in the treatment of COVID-19 patients due to their antiviral activity, ability to restore gut microbiome, modulate inflammation, ready availability, ease of administration, relatively safe and economical. The recommendations regarding the strain, dose and duration of probiotic are lacking. However, given the large experience of clinical usage, and evidence for beneficial effects in the various clinical settings, Lactobacillus and Bifidobacterium can safely be used.

\section{Acknowledgements}

The authors declare that there are no conflicts of interest.

Both authors contribute significantly to this manuscript.

\section{References}

1. Infusino F, Marazzato M, Mancone M, et al. (2020) Diet supplementation, probiotics, and nutraceuticals in SARS-CoV-2 infection: a Scoping Review. Nutrients 12, 1718. doi: 10. 3390/nu12061718.

2. Castagnoli R, Votto M, Licari A, et al. (2020) Severe Acute Respiratory Syndrome Coronavirus 2 (SARS-CoV-2) infection in children and adolescents: a systematic review. JAMA Pediatr 174, 882-889. 
3. Lu X, Zhang L, Du H, et al. (2020) SARS-CoV-2 infection in children. $N$ Engl J Med 382, 1663-1665.

4. Meena J, Yadav J, Saini L, et al. (2020) Clinical features and outcome of SARS-CoV-2 infection in children: a systematic review and meta-analysis. Indian Pediatr 57, 820-826.

5. Ma X, Liu S, Chen L, et al. (2020) The clinical characteristics of pediatric inpatients with SARS-CoV-2 infection: a meta-analysis and systematic review. J Med Virol 93, 234-240.

6. Wang Y, Lu X, Li Y, et al. (2020) Clinical course and outcomes of 344 intensive care patients with COVID-19. Am J Respir Crit Care Med 201, 1430-1434.

7. Auld SC, Caridi-Scheible M, Blum JM, et al. (2020) ICU and ventilator mortality among critically Ill adults with coronavirus disease 2019. Crit Care Med 48, e799-e804.

8. Yang X, Yu Y, Xu J, et al. (2020) Clinical course and outcomes of critically ill patients with SARS-CoV-2 pneumonia in Wuhan, China: a single-centered, retrospective, observational study. Lancet Respir Med 8, 475-481.

9. Petrilli CM, Jones SA, Yang J, et al. (2020) Factors associated with hospital admission and critical illness among 5279 people with coronavirus disease 2019 in New York City: prospective cohort study. BMJ 369, m1966.

10. Liu J, Li S, Liu J, et al. (2020) Longitudinal characteristics of lymphocyte responses and cytokine profiles in the peripheral blood of SARS-CoV-2 infected patients. EBioMedicine $\mathbf{5 5}, 102763$.

11. Wang J, Jiang M, Chen X, et al. (2020) Cytokine storm and leukocyte changes in mild versus severe SARS-CoV-2 infection: Review of 3939 COVID-19 patients in China and emerging pathogenesis and therapy concepts. J Leukoc Biol.

12. Wu H, Zhu H, Yuan C, et al. (2020) Clinical and immune features of hospitalized pediatric patients with Coronavirus Disease 2019 (COVID-19) in Wuhan, China. JAMA Netw Open 3, e2010895.

13. Soy M, Keser G, Atagunduz P, et al. (2020) Cytokine storm in COVID-19: pathogenesis and overview of anti-inflammatory agents used in treatment. Clin Rheumatol 39, 2085-2094.

14. Pouletty M, Borocco C, Ouldali N, et al. (2020) Paediatric multisystem inflammatory syndrome temporally associated with SARS-CoV-2 mimicking Kawasaki disease (Kawa-COVID19): a multicentre cohort. Ann Rheum Dis 79, 999-1006.

15. Whittaker E, Bamford A, Kenny J, et al. (2020) Clinical characteristics of 58 children with a pediatric inflammatory multisystem syndrome temporally associated with SARS-CoV-2.JAMA.

16. Dhar D \& Mohanty A (2020) Gut microbiota and Covid-19possible link and implications. Virus Res 285, 198018.

17. Conte L \& Toraldo DM (2020) Targeting the gut-lung microbiota axis by means of a high-fibre diet and probiotics may have anti-inflammatory effects in COVID-19 infection. Ther Adv Respir Dis 14, 1753466620937170.

18. Riphagen S, Gomez X, Gonzalez-Martinez C, et al. (2020) Hyperinflammatory shock in children during COVID-19 pandemic. Lancet 395, 1607-1608.

19. Feldstein LR, Rose EB, Horwitz SM, et al. (2020) Multisystem inflammatory syndrome in US children and adolescents. N Engl J Med 383, 334-346.

20. Belot A, Antona D, Renolleau S, et al. (2020) SARS-CoV-2related paediatric inflammatory multisystem syndrome, an epidemiological study, France, 1 March to 17 May 2020. Euro Surveill 25, 2001010. doi: 10.2807/1560-7917.ES.2020.25.22. 2001010.

21. Miller J, Cantor A, Zachariah P, et al. (2020) Gastrointestinal symptoms as a major presentation component of a novel multisystem inflammatory syndrome in children (MIS-C) that is related to COVID-19: a single center experience of 44 cases. Gastroenterology 159, 1571-1574.e2.
22. Kaushik S, Aydin SI, Derespina KR, et al. (2020) Multisystem Inflammatory Syndrome in Children (MIS-C) associated with SARS-CoV-2 infection: a multi-institutional study from New York City. J Pediatr 224, 24-29.

23. Toubiana J, Poirault C, Corsia A, et al. (2020) Kawasaki-like multisystem inflammatory syndrome in children during the covid-19 pandemic in Paris, France: prospective observational study. BMJ 369, m2094.

24. Grimaud M, Starck J, Levy M, et al. (2020) Acute myocarditis and multisystem inflammatory emerging disease following SARS-CoV-2 infection in critically ill children. Ann Intensive Care 10, 69

25. Verdoni L, Mazza A, Gervasoni A, et al. (2020) An outbreak of severe Kawasaki-like disease at the Italian epicentre of the SARS-CoV-2 epidemic: an observational cohort study. Lancet 395, 1771-1778.

26. Kim JM, Kim HM, Lee EJ, et al. (2020) Detection and isolation of SARS-CoV-2 in serum, urine, and stool specimens of COVID-19 patients from the Republic of Korea. Osong Public Health Res Perspect 11, 112-117.

27. Chen Y, Chen L, Deng Q, et al. (2020) The presence of SARSCoV-2 RNA in the feces of COVID-19 patients. J Med Virol 92 , 833-840.

28. Park SK, Lee CW, Park DI, et al. (2020) Detection of SARS$\mathrm{CoV}-2$ in fecal samples from patients with asymptomatic and mild COVID-19 in Korea. Clin Gastroenterol Hepatol 19, 1387-1394.e2

29. Baud D, Dimopoulou Agri V, Gibson GR, et al. (2020) Using probiotics to flatten the curve of coronavirus disease COVID-2019 pandemic. Front Public Health 8, 186.

30. Lin L, Jiang X, Zhang Z, et al. (2020) Gastrointestinal symptoms of 95 cases with SARS-CoV-2 infection. Gut 69, 997-1001.

31. Gupta A, Madhavan MV, Sehgal K, et al. (2020) Extrapulmonary manifestations of COVID-19. Nat Med 26, 1017-1032.

32. Dumas A, Bernard L, Poquet Y, et al. (2018) The role of the lung microbiota and the gut-lung axis in respiratory infectious diseases. Cell Microbiol 20, e12966.

33. Keely S, Talley NJ \& Hansbro PM (2012) Pulmonary-intestinal crosstalk in mucosal inflammatory disease. Mucosal Immunol 5, 7-18.

34. Salazar N, Arboleya S, Valdes L, et al. (2014) The human intestinal microbiome at extreme ages of life. Dietary intervention as a way to counteract alterations. Front Genet 5, 406.

35. Quercia S, Candela M, Giuliani C, et al. (2014) From lifetime to evolution: timescales of human gut microbiota adaptation. Front Microbiol 5, 587.

36. Deering KE, Devine A, O'Sullivan TA, et al. (2019) Characterizing the composition of the pediatric gut microbiome: a systematic review. Nutrients 12, 16. doi: 10.3390/ nu12010016.

37. Elena RM, Gabriela GD, Arnulfo GC, et al. (2019) Studying the gut microbiome of Latin America and Hispanic/Latino populations. Insight into obesity and diabetes: systematic review. Curr Diabetes Rev 15, 294-301.

38. Patel NA (2020) Pediatric COVID-19: systematic review of the literature. Am J Otolaryngol 41, 102573.

39. Guan WJ, Ni ZY, Hu Y, et al. (2020) Clinical characteristics of coronavirus disease 2019 in China. N Engl J Med 382, $1708-1720$.

40. Gu S, Chen Y, Wu Z, et al. (2020) Alterations of the gut microbiota in patients with COVID-19 or H1N1 influenza. Clin Infect Dis 71, 2669-2678.

41. Zuo T, Zhang F, Lui GCY, et al. (2020) Alterations in gut microbiota of patients with COVID-19 during time of hospitalization. Gastroenterology 159, 944-955.e8. 
42. Atal S \& Fatima Z (2020) IL-6 inhibitors in the treatment of serious COVID-19: a promising therapy? Pharmaceut Med 34, 223-231.

43. Boulware DR, Pullen MF, Bangdiwala AS, et al. (2020) A randomized trial of hydroxychloroquine as postexposure prophylaxis for Covid-19. N Engl J Med 383, 517-525.

44. Geleris J, Sun Y, Platt J, et al. (2020) Observational study of hydroxychloroquine in hospitalized patients with Covid-19. $N$ Engl J Med 382, 2411-2418.

45. Beigel JH, Tomashek KM, Dodd LE, et al. (2020) Remdesivir for the treatment of Covid-19 - Final Report. $N$ Engl J Med 383, 1813-1826

46. Goldman JD, Lye DCB, Hui DS, et al. (2020) Remdesivir for 5 or 10 days in patients with severe covid-19. N Engl JMed 383 1827-1837.

47. Wang Y, Zhang D, Du G, et al. (2020) Remdesivir in adults with severe COVID-19: a randomised, double-blind, placebo-controlled, multicentre trial. Lancet 395, 1569-1578.

48. Cao B, Wang Y, Wen D, et al. (2020) A trial of lopinavir-ritonavir in adults hospitalized with severe covid-19. NEngl JMed 382, 1787-1799.

49. Mohtadi N, Ghaysouri A, Shirazi S, et al. (2020) Recovery of severely ill COVID-19 patients by intravenous immunoglobulin (IVIG) treatment: a case series. Virology 548, 1-5.

50. Joyner MJ, Wright RS, Fairweather D, et al. (2020) Early safety indicators of COVID-19 convalescent plasma in 5,000 patients. J Clin Invest 130, 4791-4797.

51. Antwi-Amoabeng D, Kanji Z, Ford B, et al. (2020) Clinical outcomes in COVID-19 patients treated with tocilizumab: an individual patient data systematic review. I Med Virol 92, 2516-2522

52. Kumar S \& Singhi S (2013) Role of probiotics in prevention of Candida infection in critically ill children. Mycoses $\mathbf{5 6}$ 204-211.

53. Kumar S, Singhi S, Chakrabarti A, et al. (2013) Probiotic use and prevalence of candidemia and candiduria in a PICU. Pediatr Crit Care Med 14, e409-e415.

54. Kumar S, Bansal A, Chakrabarti A, et al. (2013) Evaluation of efficacy of probiotics in prevention of candida colonization in a PICU-a randomized controlled trial. Crit Care Med $\mathbf{4 1}$ $565-572$

55. Angurana SK, Bansal A, Singhi S, et al. (2018) Evaluation of effect of probiotics on cytokine levels in critically Ill children with severe sepsis: a double-blind, placebo-controlled trial. Crit Care Med 46, 1656-1664.

56. McFarland LV (2014) Use of probiotics to correct dysbiosis of normal microbiota following disease or disruptive events: a systematic review. BMJ Open 4, e005047.

57. Kristensen NB, Bryrup T, Allin KH, et al. (2016) Alterations in fecal microbiota composition by probiotic supplementation in healthy adults: a systematic review of randomized controlled trials. Genome Med 8, 52 .

58. Arribas B, Rodriguez-Cabezas ME, Comalada M, et al. (2009) Evaluation of the preventative effects exerted by Lactobacillus fermentum in an experimental model of septic shock induced in mice. Br J Nutr 101, 51-58.

59. D'Souza A, Cai CL, Kumar D, et al. (2012) Cytokines and tolllike receptor signaling pathways in the terminal ileum of hypoxic/hyperoxic neonatal rats: benefits of probiotics supplementation. Am J Transl Res 4, 187-197.

60. Khailova L, Petrie B, Baird CH, et al. (2014) Lactobacillus rhamnosus GG and Bifidobacterium longum attenuate lung injury and inflammatory response in experimental sepsis. PLOS ONE 9, e97861.

61. Arribas B, Garrido-Mesa N, Peran L, et al. (2012) The immunomodulatory properties of viable Lactobacillus salivarius ssp. salivarius CECT5713 are not restricted to the large intestine. Eur J Nutr 51, 365-374

62. Cui LH, Wang XH, Peng LH, et al. (2013) [The effects of early enteral nutrition with addition of probiotics on the prognosis of patients suffering from severe acute pancreatitis]. Zhonghua Wei Zhong Bing Ji Jiu Yi Xue 25, 224-228.

63. McNaught CE, Woodcock NP, Anderson AD, et al. (2005) A prospective randomised trial of probiotics in critically ill patients. Clin Nutr 24, 211-219.

64. Papoff P, Ceccarelli G, d'Ettorre G, et al. (2012) Gut microbial translocation in critically ill children and effects of supplementation with pre- and pro biotics. Int J Microbiol 2012, 151393.

65. Sanaie S, Ebrahimi-Mameghani M, Hamishehkar $\mathrm{H}$, et al. (2014) Effect of a multispecies probiotic on inflammatory markers in critically ill patients: a randomized, double-blind, placebo-controlled trial. J Res Med Sci 19, 827-833.

66. Timmerman HM, Niers LE, Ridwan BU, et al. (2007) Design of a multispecies probiotic mixture to prevent infectious complications in critically ill patients. Clin Nutr 26, 450-459.

67. Timmerman HM, Koning CJ, Mulder L, et al. (2004) Monostrain, multistrain and multispecies probiotics - a comparison of functionality and efficacy. Int J Food Microbiol 96, 219-233.

68. Chapman CM, Gibson GR \& Rowland I (2011) Health benefits of probiotics: are mixtures more effective than single strains? Eur J Nutr 50, 1-17.

69. Goldenberg JZ, Ma SS, Saxton JD, et al. (2013) Probiotics for the prevention of Clostridium difficile-associated diarrhea in adults and children. Cochrane Database Syst Rev, issue 5 , CD006095. doi: 10.1002/14651858.CD006095

70. Shen NT, Maw A, Tmanova LL, et al. (2017) Timely use of probiotics in hospitalized adults prevents Clostridium difficile infection: a systematic review with meta-regression analysis. Gastroenterology 152, 1889-900.e9.

71. Manzanares W, Lemieux M, Langlois PL, et al. (2016) Probiotic and synbiotic therapy in critical illness: a systematic review and meta-analysis. Crit Care 19, 262.

72. van Ruissen MCE, Bos LD, Dickson RP, et al. (2019) Manipulation of the microbiome in critical illness-probiotics as a preventive measure against ventilator-associated pneumonia. Intensive Care Med Exp 7, Suppl. 1, 37.

73. Bo L, Li J, Tao T, et al. (2014) Probiotics for preventing ventilator-associated pneumonia. Cochrane Database Syst Rev, issue 10, CD009066. doi: 10.1002/14651858.CD009066.

74. Su M, Jia Y, Li Y, et al. (2020) Probiotics for the prevention of ventilator-associated pneumonia: a meta-analysis of randomized controlled trials. Respir Care 65, 673-685.

75. Yang Z, Wu Q, Liu Y, et al. (2017) Effect of perioperative probiotics and synbiotics on postoperative infections after gastrointestinal surgery: a systematic review with meta-analysis. JPEN J Parenter Enteral Nutr 41, 1051-1062.

76. Yi LJ, Tian X, Shi B, et al. (2019) Early enteral nutrition supplemented with probiotics improved the clinical outcomes in severe head injury: some promising findings from Chinese patients. Medicine 98, e15426.

77. Gu WJ, Deng T, Gong YZ, et al. (2013) The effects of probiotics in early enteral nutrition on the outcomes of trauma: a meta-analysis of randomized controlled trials. JPEN J Parenter Enteral Nutr 37, 310-317.

78. Barraud D, Bollaert PE \& Gibot S (2013) Impact of the administration of probiotics on mortality in critically ill adult patients: a meta-analysis of randomized controlled trials. Chest $\mathbf{1 4 3}$, 646-655.

79. Dermyshi E, Wang Y, Yan C, et al. (2017) The "golden age" of probiotics: a systematic review and meta-analysis of 
randomized and observational studies in preterm infants. Neonatology 112, 9-23.

80. Singhi SC \& Kumar S (2016) Probiotics in critically ill children. F100ORes 5, F1000 Faculty Rev-407. doi: 10.12688/ f1000research.7630.1.

81. Haak BW, Prescott HC \& Wiersinga WJ (2018) Therapeutic potential of the gut microbiota in the prevention and treatment of sepsis. Front Immunol $\mathbf{9}, 2042$.

82. Kazemi A, Soltani S, Ghorabi S, et al. (2020) Effect of probiotic and synbiotic supplementation on inflammatory markers in health and disease status: a systematic review and metaanalysis of clinical trials. Clin Nutr 39, 789-819.

83. Tabrizi R, Ostadmohammadi V, Lankarani KB, et al. (2019) The effects of probiotic and synbiotic supplementation on inflammatory markers among patients with diabetes: a systematic review and meta-analysis of randomized controlled trials. Eur J Pharmacol 852, 254-264.

84. Milajerdi A, Mousavi SM, Sadeghi A, et al. (2020) The effect of probiotics on inflammatory biomarkers: a meta-analysis of randomized clinical trials. Eur J Nutr 59, 633-649.

85. Wang G, Wen J, Xu L, et al. (2013) Effect of enteral nutrition and ecoimmunonutrition on bacterial translocation and cytokine production in patients with severe acute pancreatitis. J Surg Res 183, 592-597.

86. Ang LY, Too HK, Tan EL, et al. (2016) Antiviral activity of Lactobacillus reuteri protectis against Coxsackievirus A and Enterovirus 71 infection in human skeletal muscle and colon cell lines. Virol J 13, 111.

87. Lee DK, Park JE, Kim MJ, et al. (2015) Probiotic bacteria, $B$ longum and L. acidophilus inhibit infection by Rotavirus in vitro and decrease the duration of diarrhea in pediatric patients. Clin Res Hepatol Gastroenterol 39, 237-244.

88. Anwar F, Altayb HN, Al-Abbasi FA, et al. (2020) Antiviral effects of probiotic metabolites on COVID-19. J Biomol Struct Dyn 39, 4175-4184.

89. Eguchi K, Fujitani N, Nakagawa H, et al. (2019) Prevention of respiratory syncytial virus infection with probiotic lactic acid bacterium Lactobacillus gasseri SBT2055. Sci Rep 9, 4812 .

90. Tonetti FR, Islam MA, Vizoso-Pinto MG, et al. (2020) Nasal priming with immunobiotic lactobacilli improves the adaptive immune response against influenza virus. Int Immunopharmacol 78, 106115.

91. Zelaya H, Tada A, Vizoso-Pinto MG, et al. (2015) Nasal priming with immunobiotic Lactobacillus rhamnosus modulates inflammation-coagulation interactions and reduces influenza virus-associated pulmonary damage. Inflamm Res 64, 589-602.

92. Tomosada Y, Chiba E, Zelaya H, et al. (2013) Nasally administered Lactobacillus rhamnosus strains differentially modulate respiratory antiviral immune responses and induce protection against respiratory syncytial virus infection. $B M C$ Immunol 14, 40.

93. Villena J, Vizoso-Pinto MG \& Kitazawa H (2016) Intestinal innate antiviral immunity and immunobiotics: beneficial effects against rotavirus infection. Front Immunol

7, 563 .

94. Kobayashi H, Kanmani P, Ishizuka T, et al. (2017) Development of an in vitro immunobiotic evaluation system against rotavirus infection in bovine intestinal epitheliocytes. Benef Microbes 8, 309-321.

95. Hao Q, Dong BR \& Wu T (2015) Probiotics for preventing acute upper respiratory tract infections. Cochrane Database Syst Rev, issue 2, CD006895. doi: 10.1002/14651858.CD006895.

96. Zelaya H, Alvarez S, Kitazawa H, et al. (2016) Respiratory antiviral immunity and immunobiotics: beneficial effects on inflammation-coagulation interaction during influenza virus infection. Front Immunol 7, 633.

97. Sanders ME, Merenstein DJ, Ouwehand AC, et al. (2016) Probiotic use in at-risk populations. J Am Pharm Assoc (2003) 56, 680-686.

98. Esaiassen E, Cavanagh P, Hjerde E, et al. (2016) Bifidobacterium longum subspecies infantis Bacteremia in 3 extremely preterm infants receiving probiotics. Emerg Infect Dis 22, 1664-1666.

99. Kolacek S, Hojsak I, Berni Canani R, et al. (2017) Commercial probiotic products: a call for improved quality control. A position paper by the ESPGHAN working group for probiotics and prebiotics. J Pediatr Gastroenterol Nutr 65, 117-124.

100. Cannon JP, Lee TA, Bolanos JT, et al. (2005) Pathogenic relevance of Lactobacillus: a retrospective review of over 200 cases. Eur J Clin Microbiol Infect Dis 24, 31-40.

101. Salminen MK, Rautelin H, Tynkkynen S, et al. (2004) Lactobacillus bacteremia, clinical significance, and patient outcome, with special focus on probiotic L. rhamnosus GG. Clin Infect Dis 38, 62-69.

102. Vahabnezhad E, Mochon AB, Wozniak LJ, et al. (2013) Lactobacillus bacteremia associated with probiotic use in a pediatric patient with ulcerative colitis. J Clin Gastroenterol 47, 437-439.

103. Munoz P, Bouza E, Cuenca-Estrella M, et al. (2005) Saccharomyces cerevisiae fungemia: an emerging infectious disease. Clin Infect Dis 40, 1625-1634.

104. Hennequin C, Kauffmann-Lacroix C, Jobert A, et al. (2000) Possible role of catheters in Saccharomyces boulardii fungemia. Eur J Clin Microbiol Infect Dis 19, 16-20.

105. Boyle RJ, Robins-Browne RM \& Tang ML (2006) Probiotic use in clinical practice: what are the risks? Am J Clin Nutr 83, 1256-1264; quiz 446-7.

106. Egervarn M, Danielsen M, Roos S, et al. (2007) Antibiotic susceptibility profiles of Lactobacillus reuteri and Lactobacillus fermentum. J Food Prot 70, 412-418.

107. Egervarn M, Roos S \& Lindmark H (2009) Identification and characterization of antibiotic resistance genes in Lactobacillus reuteri and Lactobacillus plantarum. J Appl Microbiol 107, $1658-1668$.

108. Zhu RF, Gao YL, Robert SH, et al. (2020) Systematic review of the registered clinical trials for coronavirus disease 2019 (COVID-19). J Transl Med 18, 274. 